\title{
Eccrine Porocarcinoma
}

National Cancer Institute

\section{Source}

National Cancer Institute. Eccrine Porocarcinoma. NCI Thesaurus. Code C5560.

A carcinoma with eccrine differentiation arising from the sweat glands. It may arise de novo or as a malignant transformation of a pre-existing poroma. It usually grows in the legs, buttocks, feet, and trunk and usually presents as an ulcerative plaque. It is characterized by the presence of intraepidermal and dermal nests of malignant epithelial cells. It may recur after excision and metastasize to the lymph nodes and less frequently to distal anatomic sites. 